\title{
Comparing the atmosphere to a bathtub: Effectiveness of analogy for reasoning about accumulation
}

Sophie Guy ${ }^{1,2 *}$, Yoshihisa Kashima ${ }^{1}$, Iain Walker ${ }^{2}$, Saffron O’Neill ${ }^{3}$

${ }^{1}$ Melbourne School of Psychological Sciences, Redmond Barry Building, University

of Melbourne, VIC, 3010, Australia

${ }^{2}$ Ecosystem Sciences CSIRO, Underwood Avenue, Floreat, WA, 6014, Australia

${ }^{3}$ Geography, Geography, College of Life \& Environmental Sciences, Amory Building, Rennes Drive, University of Exeter, EX4 4RJ, UK

${ }^{1}$ Phone: +613-8344-6377

${ }^{1}$ Fax: +613-9347-6618

Email: s.guy@student.unimelb.edu.au; ykashima@unimelb.edu.au; Iain.A.Walker@csiro.au;

S.O’Neill@exeter.ac.uk

* Corresponding author

Acknowledgements

This research was partly supported by the Australian Postgraduate Award Scholarship scheme and CSIRO Flagship Collaboration Fund Top-Up Scholarship. We thank the Editors and three anonymous reviewers for their suggestions that helped us improve the manuscript.

Understanding the process of accumulation is fundamental to recognising the magnitude and speed of emissions reduction required to stabilise atmospheric $\mathrm{CO}_{2}$ and, hence, global temperature. This research investigated the effectiveness of analogy for building understanding of accumulation among non-experts. Two studies tested the effects of analogy and graphical information on: (1) performance on a $\mathrm{CO}_{2}$ stabilisation task; and (2) preferred level of action on climate change. Study 1 was conducted with a sample of undergraduate students and Study 2, with a sample of the Australian public. In the student sample, analogical processing significantly improved task performance when information about emission rates was presented in text but not when it was presented in graph format. It was also associated with greater preference for strong action on climate change. When tested with the public, analogy and information format independently influenced task performance. Furthermore, there was a marginal effect of education such that the analogy especially might 
have helped those with at least high school attainment. Our results show that analogy can improve non-experts' understanding of $\mathrm{CO}_{2}$ accumulation but that using graphs to convey emissions rate information is detrimental to such improvements. The results should be of interest to climate change communicators, advocates, and policy-makers.

Climate change; analogy; accumulation; emissions; communication; decision-making 


\section{Public knowledge about climate change and its role in democracy}

Over the last two decades, numerous investigations (e.g., Kempton 1991;

Bostrom, Morgan et al. 1994; Sterman and Sweeney 2007; Bord et al. 2000) of public understanding of climate change in the US and Europe have concluded knowledge on the issue is patchy at best. Typical misconceptions include confusing climate change with other environmental issues such as stratospheric ozone depletion and air pollution (Bostrom, Morgan et al.; Read, Bostrom et al. 2004; Leiserowitz 2006; Whitmarsh 2009); difficulty differentiating between weather and climate (Bostrom, Morgan et al.; Read, Bostrom et al.; Gowda, Fox et al. 1997); and failing to make the link between burning fossil fuels and global warming (Kempton; Bostrom, Morgan et al.). More concerning is research showing that even highly educated adults underestimate emissions cuts needed to stabilise the atmospheric $\mathrm{CO}_{2}$ concentration even when provided with the relevant information (Sterman and Sweeney 2002; Sterman and Sweeney). The present studies build on this research by investigating whether analogy improves reasoning about emissions reduction to stabilise $\mathrm{CO}_{2}$ concentration ${ }^{1}$.

Many argue simply providing more information on an issue is insufficient to motivate widespread behavioural change (Kellstedt, Zahran et al. 2008; Brulle 2010; Wolf and Moser 2011; Whitmarsh and O'Neill 2011; Corner 2012).

Kahan and colleagues have demonstrated that cultural worldviews about what constitutes risk are more reliable predictors of climate change concern than are indicators of scientific literacy (Kahan, Wittlin et al. 2011; Kahan, Peters et al. 2012). In addition, structural barriers such as lack of alternative transport options, consumption norms, and energy intensive building design prevent people from making sustainable choices (Whitmarsh, O'Neill et al. 2011).

\footnotetext{
${ }^{1}$ Following Sterman and Sweeney (2007), the term ' $\mathrm{CO}_{2}$ ' is used here as a proxy for greenhouse gases.
} 
While information alone may be insufficient for behavioural change, increasing public knowledge on important issues remains necessary. In any democratic system, citizens vote into power political parties with different climate policies. More accurate knowledge of $\mathrm{CO}_{2}$ stocks and flows would inform climate change discourse, and may shape policy support and voting preferences. Understanding the nature of the carbon cycle makes salient the urgency of emission reductions and could lead to greater support for bold climate policies (Sterman and Sweeney 2007). Moreover, mitigation and adaptation to climate change necessarily involves trade-offs, highlighting questions about values and expanding the range of stakeholders with a claim on expertise and solutions to climate change (e.g., Lane et al. 2011; Klinsky 2012). Therefore, public participation in decision-making is crucial to successful mitigation and adaptation. From this perspective, empirically testing tools that could enhance understanding of the issue in participatory settings is useful. At least, it is important that policy makers possess basic climate science literacy since misconceptions could lead to costly delays in mitigation (Sterman 2008).

\section{Is analogy an effective tool for building public}

\section{knowledge?}

Of particular relevance here is the finding that even highly educated adults have great difficulty understanding the process of $\mathrm{CO}_{2}$ accumulation and stabilisation (e.g., Sweeney and Sterman 2000; Sterman and Sweeney 2002; Cronin, Gonzalez et al. 2009). The level of $\mathrm{CO}_{2}$ in the atmosphere at any one time is governed by stock-flow relationships in the carbon cycle and the principle of mass balance. So long as the rate flowing in (emissions) is greater than the rate flowing out (natural absorption) the amount (or 'stock') will continue to increase. The mass balance principle is that the inflow rate must equal the outflow rate in order for the concentration to stabilise.

Sterman and Sweeney (2007) examined whether highly educated adults could use information about historical emission and removal rates from the 
summary report of the Intergovernmental Panel on Climate Change (IPCC) to set an emissions target that would stabilise atmospheric $\mathrm{CO}_{2}$. Across three response formats, participants consistently failed to account for the stock-flow dynamics. Instead of depicting a rapid emissions reduction to equal removal, $70 \%$ of participants sketched an emissions trajectory either maintaining or increasing current rates. This would put us on a path of continued warming and severe impacts on human and natural systems.

The findings of Sterman and Sweeney (2007) and others (e.g., Moxnes and Saysel, 2009) paint a somewhat gloomy picture of non-experts' abilities to understand $\mathrm{CO}_{2}$ accumulation. However, closer analysis reveals that aspects of the study design could have made task success difficult. First, there was more detail and technical language than necessary. Although highly educated, the participants were novices in the areas of system dynamics and climate science. The information required to solve the stabilisation task could have been made more prominent and non-essential information, excluded. Second, the inclusion of multiple graphs representing different types of trend data added complexity. Participants were presented with five graphs when the information needed to successfully complete the task was contained in one. Furthermore, when people are asked to estimate future values from trend data, they tend to apply a correlational, "pattern-matching" heuristic to inform subsequent judgements (e.g., Lewandowsky 2011; Sterman and Sweeney 2002). In fact, Sterman and Sweeney described this phenomenon but did not control for it. The current study aims to address these issues.

Many climate change researchers have suggested the potential of analogy for building knowledge of climate phenomena (e.g., Marx, Weber et al. 2007; Bostrom 2008; Maibach, Roser-Renouf et al. 2008; Sterman 2008; Forbus and Gentner n.d.). However so far, there is no published empirical test of this claim. Thinking analogically about novel concepts helps to integrate unfamiliar phenomena into existing knowledge structures (Forbus and Gentner). Climate change is an inherently abstract phenomenon, involving an invisible substance $\left(\mathrm{CO}_{2}\right)$ causing impacts that will not be realised for generations to come. For most people, this lack of direct experience is 
possibly one of the biggest psychological barriers to taking action (Weber 2006). Learning via analogy offers a way to link climate change concepts to concrete, experience-based knowledge.

Work by Moxnes and Saysel (2009) provides some evidence that analogy can be effective for improving people's understanding of carbon accumulation. Their study was similar to Sterman and Sweeney's (2007); however, rather than sketching an emissions path, participants were asked to estimate emission rates at decadal time points. The goal was to stabilise $\mathrm{CO}_{2}$ at a specified concentration between 2040 and 2100 . Furthermore, two conditions included analogies to aid problem solving. One described the stock-flow dynamics in terms of stabilising flow in an air mattress on which children were to play. This condition made no mention of atmospheric $\mathrm{CO}_{2}$. The other asked participants to imagine the atmosphere as a balloon with two openings, one letting air in and the other, air out. While there was overestimation in all conditions, the air mattress condition was the most effective at reducing overestimations. Interestingly, the balloon analogy was even harmful, resulting in the greatest overestimation. Although these findings hint at the utility of analogies in climate change mitigation, it is important to investigate what analogy is effective under what circumstances.

Building on Sterman and Sweeney (2007) and Moxnes and Saysel (2009), the two studies reported here tested the effect of an analogy about $\mathrm{CO}_{2}$ accumulation on: (1) performance on a $\mathrm{CO}_{2}$ stabilisation task; and (2) preferences for different levels of action on climate change. They also tested the effect of presenting graphical information on stabilisation task performance. Participants were randomised to the analogy and graph conditions. Study 1 was conducted with university students and Study 2, with the Australian public. It was expected that: a) participants who received the analogy would estimate more accurate emission rates than participants who did not receive the analogy; and b) participants who received the 'graph' version of the stabilisation task would estimate higher emission rates than participants who received the 'no graph' version. Since understanding the process of carbon accumulation should highlight the urgency of acting on 
climate change, we expected a greater endorsement of strong action after the analogy than control.

\section{Study 1}

\subsection{Method}

\subsubsection{Design and data analysis}

The study used a 2 (analogy: absent, present) x 2 (task version: graph, no graph) between-subjects design.

\subsubsection{Participants and procedure}

Data collection occurred in May, 2011. This followed several extreme weather events in Australia including bushfires, floods, and a cyclone. It also followed shortly after an announcement by the Federal Government that they proposed to introduce a carbon pricing scheme.

Participants were recruited from a first year psychology course $(n=56)$ and university employment service $(n=44)$. All were students at the university where this research was conducted. Just less than half the sample was male (42\%) and the mean age of participants was 21 years (range 18 to 37 years). There was a large minority of Asian participants (43\%), reflecting the large numbers of international students at the university. The demographic characteristics did not significantly affect the results.

Data were collected via an online survey, which was completed in a computer lab at the university. Participants from the psychology course received course credit in exchange for participation and those recruited from the employment website were paid $\$ 10$. 


\subsubsection{Materials}

The study materials included the analogy (bathtub scenario and corresponding carbon accumulation information), mapping task, stabilisation task, and climate action preferences.

Analogy. The analogy conveys the stock-flow and mass balance principles of accumulation (Figure 1). Originating in the artificial intelligence literature (Feldman-Stewart, Kocovski et al. 2000), it is an established tool for explaining concepts across a range of disciplines including analogical processing (e.g., Gentner and Smith 2012), systems dynamics (e.g., Sterman and Sweeney 2007), and climate change (e.g., Forbus and Gentner n.d.). It is also used informally by climate scientists to explain the need for emissions to be rapidly reduced to zero. We extended the analogy to include a narrative about a situation in which there had been an accident at a chemical plant, requiring local residents to run water through their bathtubs to flush the plumbing system. The empirical literature on narratives indicates that they enhance message persuasiveness (e.g., Green and Brock 2000). The Flesch-Kincaid reading level statistic of the analogy was 9.2, equivalent to ninth grade, slightly higher than the eighth grade level recommended by the Australian National Health and Medical Research Council².

Mapping task. In order to facilitate deeper processing of the analogy, participants completed a "mapping" task, which follows the protocol of the empirical research on analogical reasoning (e.g., Bowdle and Gentner 1997; Kurtz, Mao et al. 2001; Gick and Holyoak 1980; Catrambone and Holyoak 1989). Following the analogy, participants were presented with a list of elements from the base analog (i.e., bathtub scenario) and asked to identify matching elements in the target analog (description of carbon accumulation). The first pair (water and carbon) was provided as an example. See Online Resource 1 for results of the mapping task.

\footnotetext{
${ }^{2}$ See Participant Information Sheet/Consent Form guidelines available from: http://hrep.nhmrc.gov.au/_uploads/files/PICF\%20Health\%20\&\%20Social\%20Science\%20for \%20Self\%20May2012_0.doc
} 
Stabilisation task. The stabilisation task required participants to estimate the rate of emissions needed to stabilise $\mathrm{CO}_{2}$ within a specified time range and was intended to tap understanding of the analogy. It was based on Sterman and Sweeney's (2007) task whereby participants were presented with an excerpt from the IPCC Summary for Policy Makers including information about accumulation and then asked to sketch their estimate of the likely trajectory of anthropogenic $\mathrm{CO}_{2}$ emissions under one of two future scenarios. The task used in the present research did not use the IPCC information. It was simplified so that it included only the information essential for solving the task, which was the stabilisation goal and information about current inflow and outflow rates. The format of the task was also varied so that one version included a graph (Figure 2) similar to Sterman and Sweeney's showing the rates of $\mathrm{CO}_{2}$ emissions and removal and the other version included the information about rates of emissions and removal in text, without a graph. The 'no graph' version read: 'At the moment, the rate of carbon going in to the atmosphere as a result of human activities is approximately 7.8 gigatons per year (GtC/yr). The rate of carbon removal from the atmosphere through natural processes is approximately $3.1 \mathrm{GtC} / \mathrm{yr} .$. . All participants read the same task instructions, which were to estimate the emissions rate needed to stabilise $\mathrm{CO}_{2}$ by 2030 .

\subsubsection{Dependent Measures}

Emissions rate estimation. Participants estimated the emission rate required to stabilise $\mathrm{CO}_{2}$ by 2030 . They recorded their estimation on a bar scale ranging from 0 to $10 \mathrm{GtC} / \mathrm{yr}$. If they had understood the analogy correctly, participants were expected to report that the future emission rate should equal the removal rate of $3.1 \mathrm{GtC} / \mathrm{yr}$.

Climate action preferences. A set of three items was borrowed from the Lowy Institute Poll (Hanson 2011), a nationally representative public opinion survey, and used to measure preferences for different levels of action on climate change. The items were: 1) Climate change is a serious and pressing 
problem. We should begin taking steps now even if this involves significant costs (act now); 2) The problems of climate change should be addressed, but its effects will be gradual, so we can deal with the problem gradually by taking steps that are low in cost (wait and see); 3) Until we are sure that climate change is really a problem, we should not take any steps that would have significant costs (go slow). Participants selected one statement that came closest to their own view.

\subsection{Results}

\subsection{1 $\mathrm{CO}_{2}$ stabilisation task}

The correct answer on the stabilisation task was that the emission rate should equal the removal rate of $3.1 \mathrm{GtC} / \mathrm{yr}$. In the analogy condition, a greater proportion of students (17\%) estimated the correct emission rate of $3.1 \mathrm{GtC} / \mathrm{yr}$ after completing the 'no graph' version of the task than after completing the graph version (0\%), $\chi^{2}(1)=4.36, p=.04, \varphi=-.30$.

Figure 3 shows the mean emission rate estimations across the four experimental conditions. A two-way factorial ANOVA with analogy (present vs. absent) and task version (graph vs. no graph) was conducted. There was no main effect of analogy $(F(1,95)=.21, p=.65)$, but a main effect of task version such that participants who received the 'no graph' version estimated lower emission rates $(M=4.63, S E=.36)$ than those who received the graph version $(M=5.66, S D=.36), F(1,95)=4.12, p=.05, \eta^{2}=.04$. There was also a significant interaction between analogy and task version, $F(1,95)=$ $5.41, p=.02, \eta^{2}=.05$. Analogical processing had an effect on emission rate estimations depending on task version: when the graph did not accompany the stabilisation task, those in the 'analogy present' condition made significantly lower estimations $(M=3.92, S D=1.92)$ than those in the 'analogy absent' condition $(M=5.34, S D=2.77), t(44.68)=2.12, p=.04$. A comparable analysis for those who received the graph version of the task indicated no significant difference between the 'analogy present' $(M=6.13$, 
$S D=2.89)$ and 'analogy absent' $(M=5.18, S D=2.37)$ groups, $t(47)=-1.25$, $p=.22$.

\subsubsection{Climate action preferences}

Understanding the stock-flow nature of $\mathrm{CO}_{2}$ could help people to understand the magnitude of emissions reduction required to stabilise global warming. Sterman and Sweeney (2007) argued that this knowledge may be the difference between supporting an 'act now' versus 'wait and see' approach to climate action. Participants were asked to indicate their preferences for different levels of action on climate change. Items were borrowed from a serial Australian opinion poll (Hanson 2011), which in 2011 showed that $41 \%$ of the Australian population was in support of acting now, $40 \%$ preferring to wait and see, and $19 \%$ wanting to go slow on climate change. The distribution of preferences across the analogy conditions is shown in Table 1. Analysis of the association between analogy and action preferences showed a positive effect of analogy $\left(\chi^{2}(2)=9.57, p=.01, \varphi=.31\right)$. A greater proportion of participants preferred acting now $(81 \%)$ after analogical processing than after no analogical processing (52\%).

Next, the relationship between analogical reasoning and preferences for climate action were analysed accounting for stabilisation task version. Since presenting graphical information hindered performance on the stabilisation task, it might also have influenced climate action preferences. In the 'analogy present' condition, there was no significant effect of task version on preferences, $\chi^{2}(2)=1.53, p=.47$. Under no analogy, a greater proportion of participants who completed the 'no graph' task supported strong action (69\%) than who completed the graph task (35\%), $\chi^{2}(2)=6.24, p=.04, \varphi=.35$.

We also tested Sterman and Sweeney's (2007) notion that understanding accumulation leads to support for strong action on climate change. If analogy increased strong action support through improved understanding of accumulation, those preferring strong action should have estimated lower 
emission rates than those who preferred to 'wait and see'. The emissions estimations of participants with different action preferences were compared.

Participants supporting strong action were no more accurate in their estimations $(M=5.17, S D=2.84)$ than participants preferring to 'wait and see' $(M=5.10, S D=2.10), t(38.10)=-.15, p=.88$. (The 'go slow' group was excluded due to small sample size, $\mathrm{n}=3$.)

\subsection{Discussion}

Study 1 provided preliminary evidence that the bathtub analogy positively influenced judgements about the emissions trajectory needed to stabilise $\mathrm{CO}_{2}$, and to a lesser extent, preferences for action on climate change. There were two divergent effects of task format. Participants who received the analogy and 'no graph' version of the stabilisation task estimated the lowest emissions rate. Presenting information in graph form appears to hinder performance. Analogical processing was also associated with preference for strong climate action. There was no evidence, however, that understanding accumulation was associated with preferring strong action. There was little difference in the emission estimates of students who preferred strong action and those who preferred to 'wait and see'.

The results of Study 1 provided preliminary evidence that analogy may be useful for reasoning about $\mathrm{CO}_{2}$ stabilisation. However, the narrow range of demographic characteristics in the sample limits generalisability. It is possible that the analogy is effective only with people of a certain educational background. The purpose of Study 2 was to test the analogy with a sample of the general population and particularly, people with varied educational backgrounds. 


\section{Study 2}

\subsection{Method}

Participants were 335 members of the Australian public. The mean age was 44 years (range 18 to 86 years) and $50 \%$ were female. $11 \%$ had not completed school, $36 \%$ had completed school but not gone on to university, and $53 \%$ were tertiary educated. All states and territories were represented.

A research company was contracted to conduct data collection. Individuals who were registered with the company and over the age of 16 years were eligible to participate. Participation was voluntary and the research company paid participants a small amount on completion. Quotas were set to obtain population representativeness on sex and state of residence. We also tried to achieve representation on education levels but were not successful.

The survey materials were identical to those used in Study 1. Education level was measured with two questions, one asking participants to indicate (yes/no) (a) whether they finished school, and the second for indication (b) whether they had completed or were currently completing a university degree. Data were combined to indicate three educational levels: 1 (Didn't complete school, $11 \%$; no to both (a) and (b)), 2 (Completed school, $36 \%$; yes to (a), but no to (b)), and 3 (Tertiary educated, 53\%; yes to both).

An online survey was used because it allowed timely and efficient data collection. The rate of internet access in Australian homes is relatively high $(79 \%)$ compared to the OECD average $(72 \%)^{3}$, therefore, this method was considered to effectively reach most sectors of Australian society.

\footnotetext{
${ }^{3}$ Source: OECD Key Information and Communication Technology (ICT) Indicators, http://www.oecd.org/internet/ieconomy/oecdkeyictindicators.htm.
} 


\subsection{Results}

The sample in this study primarily differed from that in Study 1 on age, education level, and belief that climate change is occurring (details of this measure, and a comparison of the two samples, are available in Online Resource 1).

\subsection{1 $\mathrm{CO}_{2}$ stabilisation task}

In the analogy condition, a greater proportion of people who completed the 'no graph' version of the stabilisation task (11\%) correctly estimated the stabilisation rate $(3.1 \mathrm{GtC} / \mathrm{yr})$ than those who completed the graph version $(0 \%), \chi^{2}(1)=9.19, p=.002, \varphi=-.24$.

The effects of analogy (present vs. absent), task version (graph vs. no graph), and education level (did not complete school, completed school, tertiary educated) on emission rate estimations were tested using the general linear model, adjusting for age and belief in climate change. Results are shown in Figure 4. There was a main effect of analogy, $F(1,301)^{4}=3.75, p=.05, \eta^{2}=$ .01 . Participants who received the analogy estimated significantly lower emission rates $(M=5.09, S E=.28)$ than those who did not receive it $(M=$ $5.83, S E=.27$ ). The effect of stabilisation task version was also significant, $F$ $(1,301)=9.88, p=.002, \eta^{2}=.03$. Participants who completed the graph version estimated higher emission rates $(M=6.06, S E=.27)$ than those who received the 'no graph' version $(M=4.86, S E=.28)$. Of interest was the marginal three-way interaction between analogy, task version, and education level, $F(2,301)=2.82, p=.06, \eta^{2}=.02$, suggesting that the effect of analogy and task version varied by education level.

A series of separate analyses was conducted for each education level. For participants whose highest educational attainment was school completion, there was a significant interaction mirroring the results found in Study $1, F(1$, $105)=4.40, p=.04, \eta^{2}=.04$. In the analogy condition, those who completed the 'no graph' stabilisation task estimated lower emission rates $(M=3.88, S E$

\footnotetext{
${ }^{4}$ Reduced $\mathrm{n}$ reflects missing data across variables
} 
$=.52)$ than those who received the graph version $(M=5.96, S E=.50)$. Among tertiary educated participants, task version significantly influenced emission estimations. Those in the 'no graph' condition estimated lower emission rates $(M=4.79, S E=.28)$ than those in the graph condition $(M=$ 6.24, SE = .30), $F(1,166)=12.15, p=.001, \eta^{2}=.07$. Analogy and task version did not significantly impact emission estimates of participants who had not completed school (all $p>$.05). A small sample size for this group $(n=37)$ means there was reduced power to detect experimental effects.

\subsubsection{Climate action preferences}

The association between analogy and climate action preferences was investigated separately by education level (Table 1). There was a significant association only among the group that did not complete school, $\chi^{2}(2,34)=$ $6.72, p=.04$. When the analysis of preferences accounted for analogy and task version, a different picture emerged (Table 2). For school completers who received the analogy, there was a significant association between task version and action preferences: a higher proportion supported strong action in the 'no graph' condition (55\%) than in the graph condition $(27 \%), \chi^{2}(2$, $34)=6.51, p=.04$. No other tests were significant (all $p>.05$ ).

Again, we tested the notion that understanding accumulation leads to preferring strong climate action. There was no significant difference in emission estimations across the preference categories, $F(2,316)=2.34, p=$ 09 .

\subsection{Discussion}

In Study 2, analogical reasoning about $\mathrm{CO}_{2}$ accumulation significantly improved estimates of the emission rate needed to achieve stabilisation. Also, estimates decreased when information about rates was provided in text rather than graph format. There was a marginally significant interaction between analogy, information format, and education level on emission estimations. Further investigation revealed results similar to those in Study 1 
among participants whose highest education attainment was completing school. Reading the analogy and completing the 'no graph' stabilisation task resulted in the lowest emission rate estimation of all the groups.

The analogy did not directly influence preferences for action on climate change. When task version and education level were accounted for, school completers in the analogy condition were more likely to prefer strong action after completing the 'no graph' task than after the graph task.

\section{General Discussion}

The studies reported here tested the effect of analogical reasoning about $\mathrm{CO}_{2}$ accumulation on judgements of the emissions rate needed to achieve stabilisation. Understanding this process is key to appreciating the need for deep cuts to global emissions. The effect of graphical information on understanding accumulation was also tested.

In Study 1, the analogy was effective when presented in conjunction with the 'no graph' version of the stabilisation task. In Study 2, analogical processing and task version independently led to lower emission rate estimations. There was also evidence that the effectiveness of analogy and task version varied by education level. Among school completers, those who received the analogy and 'no graph' version of the stabilisation task estimated the lowest emissions rate, mirroring the findings of Study 1. Task version impacted the emission estimates of tertiary educated participants such that those who completed the 'no graph' version estimated lower emission rates than those who completed the graph version. No effects were found among people who did not complete school, however, this group was underpowered by a small sample size.

In Study 1, students who read the analogy were more likely to support strong climate action. While there was no direct effect of analogy on action preferences in Study 2, analogy was effective when accounting for education 
level and task version. Again, school completers in the analogy condition were more likely to prefer strong action after completing the 'no graph' task.

The differential effects of analogy by education level in Study 2 are noteworthy. Small sample size in the least educated group makes interpretation difficult. However, it is plausible that the text was too difficult for this group (Paasche-Orlow et al. 2003). Among school completers, the analogy improved emission estimations when presented in conjunction with the 'no graph' stabilisation task. In contrast, only task version impacted stabilisation judgements among tertiary educated participants, with those completing the 'no graph' version estimating lower rates. It is plausible that this group was more knowledgeable about emission targets at the outset. The relationship between levels of education and knowledge of climate change has been documented elsewhere (e.g., Tobler et al. 2012; O'Connor et al. 1999). Prompting the issue of emission targets may have been sufficient to elicit lower estimations. The present findings suggest that the analogy may be most effective among people with a moderate level of education. It would be worthwhile to test the analogy with a sample more representative of population education levels.

Analogical processing influenced stabilisation task performance and climate action preferences (in Study 1); however, preferences were not associated with task performance. This suggests that another feature of the analogy or another unmeasured construct, besides accumulation comprehension, influenced preferences for action on climate change. Addressing this inconsistency offers another fruitful avenue of future research.

A robust finding was the detrimental effect of graphical information on task performance. It is consistent with other research showing that people often apply a correlational heuristic when presented with line graphs and asked to make predictions of future trends (Sterman and Sweeney 2007; Lewandowsky 2011). While some visual representations of statistical information can be helpful in certain risk communication contexts (e.g., Garcia-Retamero and Galesic 2010; Ancker et al. 2006), depicting flow rates 
in line graphs in the context of $\mathrm{CO}_{2}$ accumulation seems to be problematic in climate change communication. We would recommend that communicators avoid using this graph format to convey stock-flow information to lay audiences.

Past research on public understanding of climate processes has shown that even people highly literate in maths and sciences have difficulty estimating the size of emissions reduction required to stabilise global warming (e.g., Sterman and Sweeney 2007). Our results, while mixed, paint a more optimistic picture of the potential for non-experts to understand stabilisation. They suggest that two factors can improve accuracy: (1) analogical processing of accumulation information; and (2) avoiding the use of line graphs to present emission rate information. Future research should focus on ways to facilitate deeper analogy comprehension and the effectiveness of analogy in participatory settings. 


\section{References}

Ancker JS, Senathirajah Y, Kukafka R, Starren JB (2006) Design features of graphs in health risk communication: a systematic review. Journal of the American Medical Informatics Association 13 (6): 608-618

Bord RJ, O’Connor RE, Fisher A (2000) In what sense does the public need to understand global climate change? Public Understanding of Science 9(3): 205-218

Bostrom A (2008) Lead is like mercury: risk comparisons, analogies and mental models. Journal of Risk Research 11(1): 99-117

Bostrom A, Morgan M, Fischoff B, Read D (1994) What do people know about global climate change? 1. Mental models. Risk Analysis 14(6): 959-970

Bowdle B, Gentner D (1997) Informativity and asymmetry in comparisons. Cognitive Psychology 34(3): 244-286

Brulle R (2010) From environmental campaigns to advancing the public dialog: Environmental communication for civic engagement. Environmental Communication 4(1): 82-98

Catrambone R, Holyoak K (1989) Overcoming contextual limitations on problem-solving transfer. Journal of Experimental Psychology: Learning, Memory, and Cognition 15(6): 1147-1156

Corner A (2012) Psychology: Science literacy and climate views. Nature Climate Change 2(10): 710711

Cronin M, Gonzalez C, Sterman J (2009) Why don't well-educated adults understand accumulation? A challenge to researchers, educators, and citizens. Organizational Behavior and Human Decision Processes 108(1): 116-130

Feldman-Stewart D, Kocovski N, McConnell B, Brundage M, Mackillop W (2000) Perception of quantitative information for treatment decisions. Medical Decision Making 20(2): 228-238

Forbus K, Gentner D (n.d.) Dark Knowledge in Qualitative Reasoning: A Call to Arms. http://ailab.si/qr09/papers/Forbus.pdf. Accessed 8 October 2012

Garcia-Retamero R, Galesic M (2010) Who profits from visual aids: Overcoming challenges in people's understanding of risks. Social Science \& Medicine 70(7): 1019-1025

Gentner D, Smith L (2012) Analogical reasoning. In: Ramachandran V (ed) Encyclopedia of Human Behavior. 2nd edn. Elsevier, pp 130-136

Gick ML, Holyoak KJ (1980) Analogical problem solving. Cognitive Psychology 12: 306-355

Gowda M, Fox J, Magelky R (1997) Students' understanding of climate change: Insights for scientists and educators. Bulletin of the American Meteorological Society 78(10): 2232-2240

Green M, Brock T (2000) The role of transportation in the persuasiveness of public narratives. Journal of Personality and Social Psychology 79(5): 701-721

Hanson F (2011) Australia and the World: Public Opinion and Foreign Policy. The Lowy Institute Poll. Sydney, Lowy Institute

Kahan D, Wittlin M et al (2011) The tragedy of the risk-perception commons: culture conflict, rationality conflict, and climate change. Temple University Legal Studies Research Paper (2011-26) Kahan D, Peters E et al (2012) The polarizing impact of science literacy and numeracy on perceived climate change risks. Nature Climate Change 2(10): 732-735 
Kellstedt P, Zahran S, Vedlitz A (2008) Personal efficacy, the information environment, and attitudes toward global warming and climate change in the United States. Risk Analysis 28(1): 113-126

Kempton W, (1991) Lay perspectives on global climate change* 1. Global Environmental Change 1(3): 183-208

Klinsky S (2012) Comparing public rationales for trade-offs in mitigation and adaptation climate policy dilemmas. Global Enrivonmental Change 22(4): 862

Kurtz KJ, Mao CH, Gentner D (2001) Learning by analogical bootstrapping. Journal of the Learning Sciences 10(4): 417-446

Lane SN, Odoni N, Landstrom C, Whatmore SJ, Ward N, Bradley S (2011) Doing flood risk science differently: an experiment in radical scientific method. Transactions of the Institute of British

Geographers 36(1): 15

Leiserowitz A, (2006) Climate Change Risk Perception and Policy Preferences: The Role of Affect, Imagery, and Values. Climatic Change 77(1/2): 45-72

Lewandowsky S (2011) Popular Consensus. Psychological Science 22(4): 460

Maibach E, Roser-Renouf C, Leiserowitz A (2008) Communication and Marketing As Climate Change Intervention Assets. American journal of preventive medicine 35(5): 488-499

Marx S, Weber E et al (2007) Communication and mental processes: Experiential and analytic processing of uncertain climate information. Global Environmental Change 17(1): 47-58

Moxnes E, Saysel A (2009) Misperceptions of global climate change: information policies. Climatic

Change 93(1): 15-37

O’Connor RE, Bord RJ, Fisher A (1999) Risk perceptions, general environmental beliefs, and willingness to address climate change. Risk Analysis 19(3): 461-471

Read D, Bostrom A, Morgan M, Fischoff B, Smuts T (1994) What do people know about global climate change? 2. Survey studies of educated laypeople. Risk Analysis 14(6): 971-982

Paasche-Orlow M, Taylor H, Brancati F (2003) Readability standards for informed-consent forms as compared with actual readability. New England Journal of Medicine 348(8): 721-726

Sterman J (2008) Risk communication on climate: mental models and mass balance. Science 322(5.901): 532-533

Sterman J, Sweeney L (2002) Cloudy skies: assessing public understanding of global warming. System Dynamics Review 18(2): 207-240

Sterman J, Sweeney L (2007) Understanding public complacency about climate change: Adultsí mental models of climate change violate conservation of matter. Climatic Change 80(3): 213-238

Sweeney L, Sterman J (2000) Bathtub dynamics: initial results of a systems thinking inventory. System Dynamics Review 16(4): 249-286

Tobler C, Visschers VH, Siegrist M (2012) Consumers' knowledge about climate change. Climatic Change 114 (2):189-209

Weber E (2006) Experience-based and description-based perceptions of long-term risk: Why global warming does not scare us (yet). Climatic Change 77(1): 103-120 
Whitmarsh L, O'Neill S (2011) Introduction: Opportunities for and Barriers to Engaging Individuals with Climate Change. In: Whitmarsh, L, O'Neill S, Lorenzoni, I Engaging the Public with Climate Change. Earthscan, London, 1-13

Whitmarsh L (2009) What's in a name? Commonalities and differences in public understanding of 'climate change' and 'global warming'. Public Understanding of Science 18(4): 401-420

Whitmarsh L, O'Neill S, Lorenzoni, I (2011) Conclusion: What Have We Learnt and Where do We Go from Here? In: Whitmarsh, L, O'Neill S, Lorenzoni, I Engaging the Public with Climate Change. Earthscan, London, 270-282

Wolf J, Moser SC (2011) Individual understandings, perceptions, and engagement with climate change: insights from in depth studies across the world. Wiley Interdisciplinary Reviews: Climate Change 2: 547-569 
Fig. 1 Analogy materials

Fig. 2 Graph version of stabilisation task

Fig. 3 Effects of analogy and task version on emission rate estimations

Fig. 4 Effects of analogy and task version on emission rate estimations by education level

Table 1 Distribution of climate action preferences $(\%)$ by analogy condition

\begin{tabular}{|c|c|c|c|c|}
\hline & \multicolumn{2}{|c|}{ Study 1} & \multicolumn{2}{|c|}{ Study 2} \\
\hline & \multicolumn{2}{|c|}{ Analogy } & \multicolumn{2}{|c|}{ Analogy } \\
\hline Level of action & Absent & Present & Absent & Present \\
\hline \multicolumn{5}{|c|}{ Did not complete school } \\
\hline Act now & - & - & 35 & 12 \\
\hline Wait and see & - & - & 59 & 47 \\
\hline Go slow & - & - & 6 & 41 \\
\hline \multicolumn{5}{|c|}{ Completed school } \\
\hline Act now & 52 & 81 & 37 & 41 \\
\hline Wait and see & 42 & 19 & 48 & 36 \\
\hline Go slow & 6 & 0 & 15 & 24 \\
\hline \multicolumn{5}{|c|}{ Tertiary educated } \\
\hline Act now & - & - & 55 & 63 \\
\hline Wait and see & - & - & 36 & 30 \\
\hline Go slow & - & - & 9 & 7 \\
\hline
\end{tabular}

Table 2 Distribution of climate action preferences (\%) by analogy and task version conditions for participants with different levels of education (Study 2)

\begin{tabular}{|l|c|c|c|c|}
\hline Level of action & \multicolumn{2}{|c|}{ Analogy absent } & \multicolumn{2}{c|}{ Analogy present } \\
\hline & No graph & Graph & No graph & Graph \\
\hline $\begin{array}{l}\text { Did not complete school }(n= \\
37)\end{array}$ & & & & \\
\hline Act now & 22 & 50 & 11 & 13 \\
\hline Wait and see & 67 & 50 & 44 & 50 \\
\hline Go slow & 11 & 0 & 44 & 37 \\
\hline
\end{tabular}




\begin{tabular}{|l|c|c|c|c|}
\hline Completed school $(n=120)$ & & & & \\
\hline Act now & 24 & 45 & 55 & 27 \\
\hline Wait and see & 67 & 36 & 21 & 50 \\
\hline Go slow & 9 & 18 & 24 & 23 \\
\hline Tertiary educated $(n=178)$ & & & & \\
\hline Act now & 59 & 51 & 70 & 55 \\
\hline Wait and see & 34 & 39 & 28 & 32 \\
\hline Go slow & 7 & 10 & 2 & 13 \\
\hline
\end{tabular}


Fig. 1 Analogy materials

\section{BATHTUB STORY}

The build up of carbon in the atmosphere is like the process of water flow in a bathtub. Picture a bath without the plug. If you turn the tap on a little, all the water will run straight out the drain and the water level will not increase. On the other hand, if you turn the tap on full, the water level starts to rise. This is because the drain hole can only let a certain amount of water out of the bath at any one moment. When the inflow of water from the tap is greater than the outflow through the drain, the bathtub fills up. It is also possible to adjust the tap so that the inflow is equal to the outflow, causing the water level to stabilise.

The following scenario might help you to understand the water flow process a little better:

Imagine there has been an industrial accident near where you live and the water supply to your house has been contaminated with an invisible toxin. You've been advised by the local council to turn the tap on in the bath to allow the contaminated water to run through the plumbing system.

You go to the bath, turn the tap on full and watch as the water gushes out. It's slightly smelly and unpleasant so you decide to go off and do something else while the water is running.

After a time, you come back to check on the bath situation and notice that the water has risen almost to the top! It is going to overflow if you don't act quickly to stabilise the water level. First though, you need to reduce the amount of water in the bath because it seems dangerous for it to be so full of toxic chemicals.

You turn the tap down and notice that the water level continues to increase. It's rising slower than before, but increasing nonetheless. There is still more water going into the bath than is draining out. You adjust the tap again, turning it right down, and the water level starts to lower.

When the water in the bath has decreased to about half way, you adjust the tap to stabilise the level. It takes a few adjustments to get the rate of water flowing in through the tap to equal the rate flowing out through the drain but eventually you get it. The water level is now stable and no longer threatening to overflow. This time, you stay to monitor the water flow while you wait for it to clear.

\section{CARBON ACCUMULATION}

Carbon is one of the most common chemical elements on Earth and is found in almost everything including people, plants, and rocks. It is also in the atmosphere in the form 
of a gas called 'carbon dioxide' where it prevents the Sun's heat from being reflected back into space. Most of the time this is a good thing, because it keeps the temperature within a range suitable for living things. However, the concentration of carbon in the atmosphere is now much greater than at any other time in the last 400000 years and much more heat is being trapped. This trapped heat causes the surface of the Earth to warm and the climate to change.

The concentration of carbon in the atmosphere is determined by the rate flowing in and the rate flowing out. The inflow is commonly called 'emissions' and comes from natural sources (e.g., bushfires, rotting vegetation) as well as human activities (e.g., burning fuels containing carbon). The outflow is called 'removal' and occurs through capture of carbon by plants during photosynthesis (the process by which they make food) and through absorption by the oceans.

The rate of emissions flowing into the atmosphere has been rising steadily since the late 1800 s when humans started burning large amounts of coal and petroleum. Before this time, emissions were mostly the result of natural processes and the rate flowing into the atmosphere was roughly equal to the rate that it was removed. This kept the level of carbon in the atmosphere balanced.

While there has been a sharp increase in the emissions of carbon into the atmosphere, the rate at which it is removed through natural processes has remained fairly constant. The consequence is that carbon is accumulating and the level is increasing all the time. At the moment, there is no other way of removing carbon from the atmosphere. We are, however, able to control the rate that carbon is emitted into the atmosphere. 
(original survey items created in Qualtrics; image copied from pdf document)

Fig. 2 Graph version of stabilisation task

GRAPH VERSION

\section{CARBON STABILISATION}

The following task involves thinking about the rate of emissions needed to stabilise the level of carbon in the atmosphere.

Governments around the world have been trying to decide on the level at which carbon in the atmosphere should be stabilised. It has been argued that stabilising carbon at the current level, so that it does not increase anymore, by 2030 is a realistic target.

The graph shows the rate that carbon has been flowing into and out of the atmosphere since 1970 , measured in gigatons of carbon per year $(G+C / y r)$. The solid line represents the rate of emissions from human activities and the dotted line represents the rate of removal through natural processes.

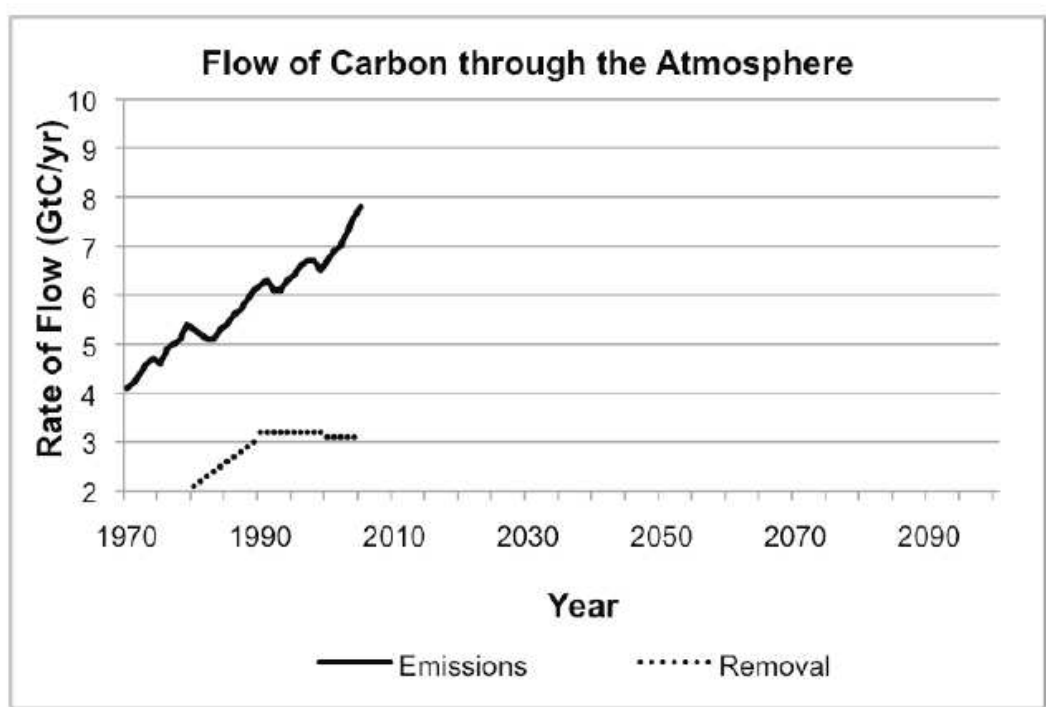

What do you think will be the future (i.e., next 10 to 15 years) rate of carbon removal from the atmosphere per year? Indicate your answer by moving the slider on the bar below.

\begin{tabular}{r|llllllllllllll} 
& 0 & 1 & 2 & 3 & 4 & 5 & 6 & 7 & 8 & 9 & 10 \\
\hline $\begin{array}{r}\text { Gigatons of carbon } \\
\text { per year }\end{array}$ & & & & & & & & & & & & & & \\
\hline
\end{tabular}

If $7.8 \mathrm{GtC} / \mathrm{yr}$ is the current rate of carbon emissions going in to the atmosphere, what do you think is the future (i.e., next 10 to 15 years) rate needed to stabilise the level in the atmosphere by 2030 ? Indicate your answer by moving the slider on the bar below.

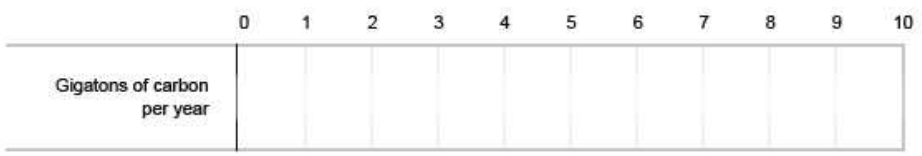


(figure created in SPSS version 21)

Fig. 3 Effects of analogy and task version on emission rate estimations

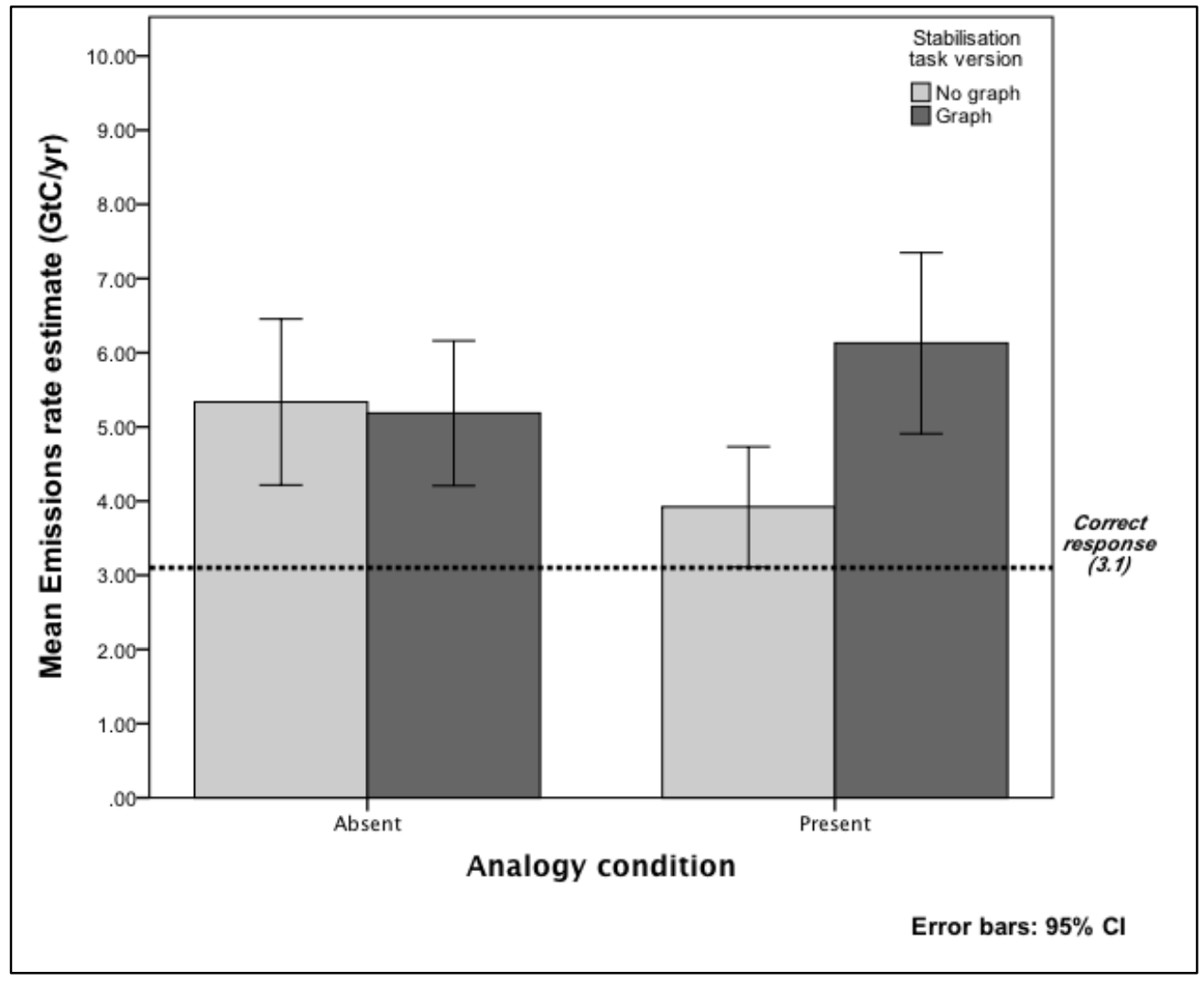


(figure created in SPSS version 21)

Fig. 4 Effects of analogy and task version on emission rate estimations by education level

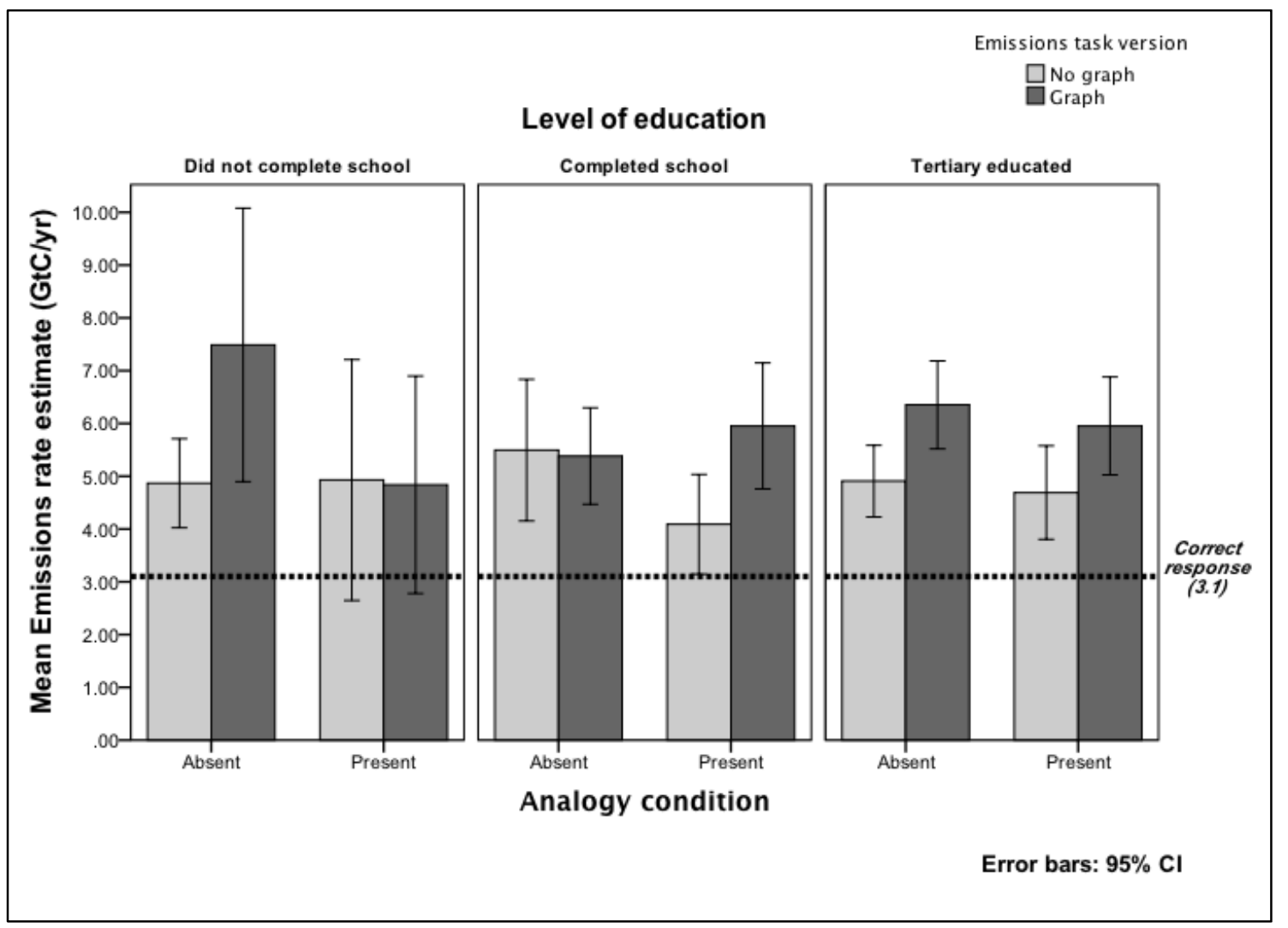

